\title{
Antiallergic effect of ginseng fermented with Ganoderma lucidum
}

\author{
Eun-Ah Bae*, Hien-Trung Trinh*, Young Kyung Rhee**, \\ Young-Chul Lee** and Dong-Hyun Kim**\# \\ *Department of Food and Nutrition, Kyung Hee University, 1, Hoegi, Dongdaemun-ku, Seoul 130-701, Korea; \\ **Korea Food Research Institute, San 46-1, Baekhyun, Bundang-Ku, Seoungnam-Shi 463-420, Korea.
}

(Received January 17, 2008; Accepted February 25, 2008)

\begin{abstract}
Ginseng (the root of Panax ginseng CA Meyer, family Araliacease), which is used in Korea, China and Japan as a herbal medicine, was fermented with Ganoderma lucidum (GL) and their antiallergic effects were investigated. Of GLs used for fermentation, KCTC 6283 potently produced ginsenoside Rh2, followed by KFRI M101. KCTC 6532, and ginsenoside Rd, followed by KFRI M101. Oral administration of these fermented ginseng extracts inhibited allergic reactions, passive cutaneous anaphylaxis reaction induced by IgE and scratching behaviors induced by compound 48/80. Of them, the ginseng extract fermented by KCTC 6532 and KFRI M101 potently inhibited allergic reactions compared to that fermented by KCTC 6283. These findings suggest that the fermentation of ginseng with GL can increase its antiallergic activity and the increment of its antiallergic effect may be due to the biotransformation of ginseng saponins to ginsenosides $\mathrm{Rd}$ and $\mathrm{Rh} 2$.
\end{abstract}

Key words : ginseng, Ganoderma lucidum, antiallergic effect, fermentation.

\section{INTRODUCTION}

Ginseng (the root of Panax ginseng C.A. Meyer, Family Araliaceae) is frequently used as a crude substance, and taken orally in Asian countries as a traditional medicine. The major components of interest in ginseng are ginsenosides, which contain an aglycone with a dammarane skeleton $^{1,2)}$. These ginsenosides have been previously reported to show various biological activities, which include anti-inflammatory ${ }^{3)}$ and anti-tumor activities (i.e., the inhibition of tumor-induced angiogenesis and the prevention of tumor invasion and metastasis $)^{4,5)}$. The pharmacological actions of these ginsenosides have been explained on the basis of the biotransformation of ginsenosides by human intestinal microflora ${ }^{7-10}$. For example, the protopanaxadiol ginsenosides are transformed to 20$O$ - $\beta$-D-glucopyranosyl-20(S)-protopanaxadiol (compound $\mathrm{K})$ by human intestinal bacteria. The transformed compound $\mathrm{K}$ induces antimetastatic and/or anticarcinogenic effects by blocking tumor invasion or by preventing chromosomal aberration and tumorigenesis ${ }^{5,11)}$. To increase the pharmacological effect of ginseng, the ginsengs fer-

\footnotetext{
\# To whom correspondence should be addressed.

(Tel) +82-2-961-0374; (Fax) +82-2-957-5030

(E-mail) dhkim@khu.ac.kr
}

mented by lactic acid bacteria have been developed. However, the studies on the ginsengs fermented by mushrooms, particularly, Ganoderma lucidum Karst. (GL, family Polyporaceae), which has been frequently used in traditional Chinese medicine for hepatitis, tumor and immunological disorders ${ }^{12,13)}$, have not been performed.

Therefore, we fermented ginseng with GLs, and investigated their antiallergic effects.

\section{MATERIALS AND METHODS}

\section{Materials}

Dulbecco's modified Eagles medium (DMEM), fetal bovine serum, dinitrophenol-human serum albumin (DNP-HSA), ovalbumin (OVA), cremophor EL and compound 48/80 were purchased from Sigma Co. (St. Louis, MO, USA).

The mycelia of G. lucidum KCTC 6283, KCTC 6532 (from the Biological Resource Center, Daejeon, Chungnam), and KFRI M101 (Korea Food Research Institute, Sungnam, Gyunggi, Korea) were used.

\section{Fermentation of ginseng by GL}

Raw ginseng (4 year-old the root of Panax ginseng C.A. Meyer, Ansung Ginseng Cooperative Association, Korea) 
were finely washed with distilled water, chopped and dried at $60^{\circ} \mathrm{C}$ by hot-air dryer. The dried ginseng flakes $(100 \mathrm{~g})$ were mixed well with $210 \mathrm{ml}$ of distilled water, and autoclaved in $121^{\circ} \mathrm{C}$ for $15 \mathrm{~min}$. A seed mycelia disc $(20 \mathrm{~mm})$ of $G$. lucidum was inoculated in the autoclaved ginseng media and then incubated in growth chamber for 35 days. The sterilized ginsengs with or without fermentation were then extracted with $100 \mathrm{ml}$ of distilled water twice. The water extracts were extracted with ethyl acetate, and then concentrated in vacuo. These were used as non-fermented and fermented agents.

\section{Extraction of saponin from fermented ginseng and determination of its ginsenoside content}

The ginseng samples with and without fermentation were homogenized and freeze-dried. The dried powder (2 g) was extracted with $30 \mathrm{ml}$ of $80 \%$ methanol in boiling water for $1 \mathrm{~h}$ and filtered through filter paper (Whatman No. 1). Its insoluble residue was extracted with the same solvent. The filtrate was concentrated by a rotary evaporator at $60^{\circ} \mathrm{C}$, readjusted with $10 \mathrm{ml}$ of distilled water, and extracted with $10 \mathrm{ml}$ of diethyl ether twice. The aqueous layer was extracted with $10 \mathrm{ml}$ of water-saturated butanol for 4 times. The combined butanol layer was concentrated by a rotary evaporator. The concentrate was dissolved in methanol and used as a saponin fraction.

The content of ginsenosides in the saponin fraction was analyzed by JASCO HPLC system (Jasco system, Japan) consisted of Inteligent UV/VIS detector UV-975, Inteligent HPLC pump PU-980, and column oven CO-965 [column, $\mu$-Bondapak C18 $(3.9 \times 300 \mathrm{~mm}$, Waters, Irland), mobile phase, distilled water-acetonitrile gradient system [0-30 min, $19 \%$ actonitrile; $30-31 \mathrm{~min}, 19-30 \%$ acetonitrile (linear gradient); 31-65 min 30\% acetonitrile]; flow rate, 1.5 $\mathrm{ml} / \mathrm{min}$; detection, wavelength, $203 \mathrm{~nm}$ ].

\section{Animals}

Male and female ICR mice (20 - $22 \mathrm{~g}$ ) and male BALB/ c mice (18 - $22 \mathrm{~g}$ ) were supplied from Charles River Orient Experimental Animal Breeding Center (Seoul, Korea). All animals were housed in wire cages at $20-22^{\circ} \mathrm{C}$, a relative humidity of $50 \pm 10 \%$ humidity, a frequency of air ventilation of 15-20 times/h, and $12 \mathrm{~h}$ illumination (07:00 -19:00; intensity, 150-300 Lux), fed standard laboratory chow (Charles River Orient Experimental Animal Breeding Center, Seoul Korea) and allowed water ad libitum. All procedures relating to the animals and their care conformed to the international guidelines 'Principles of Laboratory Animals Care' (NIH publication no. 85-23, revised
1985).

\section{Assay of Passive Cutaneous Anaphylaxis (PCA) Reaction}

An IgE-dependent cutaneous reaction was measured according to the previous method of Choo et al. ${ }^{14)}$ The male ICR mice were injected intradermally with $10 \mu \mathrm{g}$ of anti-DNP IgE into each of two dorsal skin sites that had been shaved $48 \mathrm{~h}$ earlier. The sites were outlined with a water-insoluble red marker. Forty-eight hours later each mouse received an injection of $200 \mu \mathrm{l}$ of $3 \%$ Evans blue PBS containing $200 \mu \mathrm{g}$ of DNP-HSA via the tail vein. The test agents were orally administered $1 \mathrm{~h}$ prior to DNP-HSA injection. Thirty min after DNP-HSA injection, the mice were sacrificed and their dorsal skins were removed for measurement of the pigment area. After extraction with $1 \mathrm{ml}$ of $1.0 \mathrm{~N} \mathrm{KOH}$ and $4 \mathrm{ml}$ of a mixture of acetone and $0.6 \mathrm{~N}$ phosphoric acid (13:5), the amount of dye was determined colorimetrically (the absorbance at $620 \mathrm{~nm})$.

\section{Scratching Behavioral Experiment}

The behavioral experiments were performed according to the method of Choo et al. ${ }^{14)}$ The male BALB/c mice were put into acrylic cages $(22 \times 22 \times 24 \mathrm{~cm})$ for about 10 min for acclimation. The rostral part of the skin on the back of mice was clipped, and $50 \mu \mathrm{g} / 50 \mu \mathrm{l}$ of compound $48 / 80$ for each mouse was intradermally injected with the use a 29 gauge needle. The scratching agent was dissolved in saline and then used. Control mice received a saline injection in the place of the scratching agent. Immediately after the intradermal injection, the mice (one animal/cage) were put back into the same cage and, for the observation of scratching; their behaviors recorded using an 8-mm video camera (SV-K80, Samsung, Seoul, Korea) under unmanned conditions. Scratching of the injected site by the hind paws was counted and compared with that of other sites, such as the ears. Each mouse was used for only one experiment. The mice generally showed several scratches for $1 \mathrm{~s}$, and a series of these behaviors was counted as one incident of scratching for $60 \mathrm{~min}$. The test agents were orally administered $1 \mathrm{~h}$ before the scratching agent.

\section{Statistics}

All the data were expressed as the mean \pm standard deviation, and statistical significance was analyzed by one way ANOVA followed by Student-Newman-Keuls test. 
Table 1. The content of ginsenosides in the ginsengs fermented by G. lucidum mycelia on HPLC.

\begin{tabular}{lcccccccc}
\hline \hline & \multicolumn{9}{c}{ Content $(\%)$} \\
\cline { 2 - 9 } & Rb2+Rb3 & Rc & Rd & Rg3 & Rh2 & $\operatorname{Re}$ & Rg1 & Rg2+Rh1 \\
\hline S. ginseng ${ }^{\text {a) }}$ & 3.02 & 4.12 & 1.76 & 0.79 & - & 2.50 & 2.85 & 0.65 \\
KCTC 6283 & 1.97 & 1.29 & 1.31 & 0.28 & 0.05 & 0.69 & 1.71 & 0.65 \\
KCTC 6532 & 0.56 & 0.40 & 7.91 & 0.73 & 0.02 & 1.08 & 1.29 & 0.35 \\
KFRI M101 & 2.52 & 1.51 & 6.68 & 0.67 & 0.04 & 2.16 & 2.56 & 0.62 \\
\hline
\end{tabular}

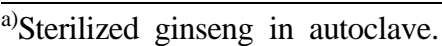

${ }^{b)}$ Not detected.

Table 2. Inhibitory effect of the ginseng fermented with and without GL on IgE-induced passive cutaneous anaphylaxis in mice.

\begin{tabular}{lcc}
\hline \hline \multicolumn{1}{c}{ Agent } & $\begin{array}{c}\text { Dose } \\
(\mathrm{mg} / \mathrm{kg})\end{array}$ & $\begin{array}{c}\text { Inhibition } \\
(\%)\end{array}$ \\
\hline Medium alone & 100 & $12 \pm 6^{\mathrm{a}, \mathrm{b}}$ \\
Sterilized ginseng flake & 100 & $20 \pm 7^{\mathrm{b}, \mathrm{c}}$ \\
Ginseng fermented by KCTC 6283 & 20 & $7 \pm 5^{\mathrm{a}}$ \\
& 100 & $25 \pm 9^{\mathrm{b}, \mathrm{c}}$ \\
Ginseng fermented by KCTC 6532 & 20 & $10 \pm 7^{\mathrm{a}}$ \\
& 100 & $31 \pm 7^{\mathrm{c}, \mathrm{d}}$ \\
Ginseng fermented by KFRI M101 & 20 & $12 \pm 6^{\mathrm{a}, \mathrm{b}}$ \\
& 100 & $43 \pm 5^{\mathrm{d}}$ \\
Azelastine & 10 & $76 \pm 6^{\mathrm{e}}$ \\
\hline
\end{tabular}

The ginsengs with and without autoclave sterilization were extracted with distilled water and used as ginseng and sterilized ginseng flake extracts. The extract was fermented with Ganoderma lucidum (GL) for 35 days at $25^{\circ} \mathrm{C}$, concentrated and used as GL-fermented ginseng extract. The positive agent was orally administered $10 \mathrm{mg} / \mathrm{kg}$ of azelastine. Each extract $(20 \mathrm{mg} / \mathrm{kg}$ and $100 \mathrm{mg} / \mathrm{kg}$ ) was orally administered $1 \mathrm{~h}$ prior to DNP-HSA injection. Normal group was treated with vehicle alone. All values are means \pm S.D. $(n=5){ }^{a, b, c, d, e}$ Items with the same letter are not significantly different.

\section{Results and Discussion}

To investigate the relationship between antiallergic effect of GL-fermented ginseng and its saponin biotransformation, we fermented ginseng by GL, extracted with $\mathrm{BuOH}$ and then analyzed their saponin contents (Table 1). GL transformed ginseng saponins to their hydrophobic metabolites. Of them, KCTC 6532 and KFRI M101 potently produced ginsenoside Rd and KCTC 6283 and KFRI M101 potently produced ginsenoside Rh2. However, instead of the content increment of these ginsenosides, the content of hydrophilic ginsenosides $\mathrm{Rb} 2$ and $\mathrm{Rc}$ was decreased.

In addition, we investigated the antiallerigc effect of GL-fermented ginsengs in mouse passive cutaneous anaphylaxis reaction induced by IgE-antigen complex (Table
Table 3. Inhibitory effect of the ginsengs fermented with and without GL on compound 48/80-induced scratching behaviors in mice.

\begin{tabular}{lcc}
\hline \hline & $\begin{array}{c}\text { Dose } \\
(\mathrm{mg} / \mathrm{kg})\end{array}$ & $\begin{array}{c}\text { Inhibition } \\
(\%)\end{array}$ \\
\hline Medium alone & 100 & $13 \pm 5^{\mathrm{a}, \mathrm{b}}$ \\
Sterilized ginseng flake & 100 & $17 \pm 3^{\mathrm{b}, \mathrm{c}}$ \\
Ginseng fermented by KCTC 6283 & 20 & $9 \pm 5^{\mathrm{a}}$ \\
& 100 & $29 \pm 7^{\mathrm{c}, \mathrm{d}}$ \\
Ginseng fermented by KCTC 6532 & 20 & $12 \pm 3^{\mathrm{a}, \mathrm{b}}$ \\
& 100 & $35 \pm 3^{\mathrm{d}}$ \\
Ginseng fermented by KFRI M101 & 20 & $11 \pm 4^{\mathrm{a}}$ \\
& 100 & $45 \pm 5^{\mathrm{e}}$ \\
Azelastine & 10 & $47 \pm 4^{\mathrm{e}}$ \\
\hline
\end{tabular}

The ginsengs with and without autoclave sterilization were extracted with distilled water and used as ginseng and sterilized ginseng flake extracts. The extract was fermented with Ganoderma lucidum (GL) for 35 days at $25^{\circ} \mathrm{C}$, concentrated and used as GL-fermented ginseng extract. Each extract $(20 \mathrm{mg} / \mathrm{kg}$ and $100 \mathrm{mg} / \mathrm{kg}$ ) was orally administered. The positive agent was orally administered $10 \mathrm{mg} / \mathrm{kg}$ of azelastine. The scratching agent compound 48/80 $(50 \mu \mathrm{g} / 50 \mu \mathrm{l})$ for each mouse was intradermally injected $1 \mathrm{~h}$ after the administration of test agents. Normal group was treated with vehicle (saline) alone and control group was with compound $48 / 80$ and vehicle. All values are means \pm S.D.

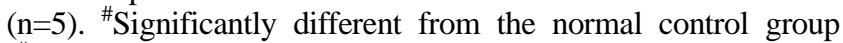
$\left({ }^{\#} P<0.05\right)$. *Significantly different from compound $48 / 80$ alone stimulated (control) group $(* \mathrm{p}<0.05)$

2). Fermented ginsengs potently inhibited the PCA reaction in mice, compared to that of non-fermented ginseng. Of them the ginseng fermented by KFRI M101 most potently inhibited the PCA reaction. However, these inhibitory effects were weak, compared with that of azelastine.

The inhibitory effect of the fermented ginsengs in the compound 48/80-induced scratching behavior mouse model was also investigated (Table 3). Fermented ginsengs also potently inhibited the scratching behaviors, compared to that of non-fermented ginseng. Of them, the ginseng fermented by KFRI M101 at a dose of $100 \mathrm{mg} / \mathrm{kg}$ 
most potently inhibited the scratching behaviors, with a value of $45 \%$ (azelastine at a dose of $10 \mathrm{mg} / \mathrm{kg}$ inhibited it by $47 \%$ ).

Allergic reactions including rhinitis, asthma and anaphylaxis produced many inflammatory mediators and caused scratching, inflammation, pain and increase of vascular permeability ${ }^{15-17)}$. Anti-histamines, steroids and immunosuppressants did not only have potent anti-inflammatory effects, but also cause intense side reactions ${ }^{16,18,19)}$. Therefore, herbal medicines have been advanced for allergic diseases, and its effectiveness has received increasing attention. Ginseng exhibited the anti-inflammatory and antiallerigc activities. These effects of the ginseng were increased by the fermentation of lactic acid bacteria. The pharmacological effects of many herbal medicines were also increased by intestinal bacteria ${ }^{20,21)}$. Based on these findings, we fermented the ginseng by GLs. The GL fermentation of the ginseng more potently inhibited PCA reaction induced by IgE-antigen complex as well as scratching behaviors induced by compound 48/80 than non-fermented one. Of GLs, KFRI M101 most potently increased the antiallergic effect. KFRI M101 potently produced ginsenosides $\mathrm{Rh} 2$ and $\mathrm{Rd}$, compared with other GLs. Based on these findings, the fermentation of ginseng with GL can increase its antiallergic effect and its increment may be due to the biotransformation of ginseng saponins to ginsenosides $\mathrm{Rd}$ and $\mathrm{Rh} 2$.

\section{REFERENCES}

1. Shibata, S., Fujita, M., Itokawa, H., Tanaka, O. and Ishii, T. : Panaxadiol, a sapongenin of ginseng roots (1). Chem. Pharm. Bull. 11, 759-764 (1963).

2. Tanaka, N., Tanaka, O. and Shibata, S. : Chemical studies on the oriental plant drugs. XXVIII. Saponins and sapogenins of ginseng; Stereochemistry of sapogenin of ginsenoside Rb1, Rb2 and Rc. Chem. Pharm. Bull. 20, 1212-1216 (1972).

3. Wu, J.Y., Gardner, B.H., Murphy, C.I., Seals, J.R., Kensil, C.R., Recchia, J., Beltz, G.A., Newman, G.W. and Newman, M.J. : Saponin adjuvant enhancement of antigen-specific immune responses to an experimental HIV-1 vaccine. $J$. Immunol. 148, 1519-1525 (1992).

4. Mochizuki, M., Yoo, C.Y., Matsuzawa, M. K., Sato, K., Saiki, I., Tono-oka, S., Samukawa, K. and Azuma, I. : Inhibitory effect of tumor metastasis in mice by saponins, ginsenoside $\mathrm{Rb} 2,20(\mathrm{R})-$ and 20(S)-ginsenoside Rg3, of Red ginseng. Biol. Pharm. Bull. 18, 1197-1202 (1995).

5. Wakabayashi, C., Hasegawa, H., Murata, J. and Saiki, I. : In vivo antimetastatic action of ginseng protopanaxadiol saponins is based on their intestinal bacterial metabolites after oral administration. Oncology Res. 9, 411-417 (1998).

6. Akao, T., Kanaoka, M. and Kobashi, K. : Appearance of compound $\mathrm{K}$, a major metabolite of ginsenoside $\mathrm{Rb} 1$ by intestinal bacteria, in rat plasma after oral administrationmeasurement of compound $\mathrm{K}$ by enzyme immunoassay. Biol. Pharm. Bull. 21, 245-249 (1988).

7. Akao, T., Kida, H., Kanaoka, M., Hattori, M. and Kobashi, $\mathrm{K}$. : Intestinal bacterial hydrolysis is required for the appearance of compound $\mathrm{K}$ in rat plasma after oral administration of ginsenoside Rb1 from Panax ginseng. J. Pharm. Pharmacol. 50, 1155-1160 (1988).

8. Bae, E.A., Kim, N.-Y., Han, M. J., Choo, M.-K. and Kim, D.$\mathrm{H}$. : Transformation of ginsenosides to compound $\mathrm{K}$ by lactic acid bacteria of human intestine J. Microbiol. Biotechnol. 13, 9-14 (2000).

9. Bae, E.A., Han, M.J., Choo, M.K., Park, S.Y. and Kim, D.H. : Metabolism of 20(S)- and 20(R)-ginsenoside Rg3 by human intestinal bacteria and its relation to in vitro biological activities. Biol. Pharm. Bull. 25, 58-63 (2002).

10. Hasegawa, H., Sung, J.H. and Benno, Y. : Role of human intestinal Prevotella oris in hydrolyzing Ginseng saponis. Planta Med. 63, 436-440 (1997).

11. Lee, S.J., Sung, J. H., Lee, S.J., Moon, C.K. and Lee, B.H. : Antitumor activity of a novel ginseng saponin metabolite in human pulmonary adenocarcinoma cells resistant to cisplatin. Cancer Lett. 144, 39-43 (1999).

12. Lin, Z.B. and Zhang, H.N. : Anti-tumor and immunoregulatory activities of Ganoderma lucidum and its possible mechanisms, Acta Pharmacol. Sin. 25, 1387-1395 (2004).

13. Sung, S.K., Kim, M.J., Lee, D.H., Choung, S.Y., Kim, B.K. and Kim, H.W. : $\beta$-Glucan of Ganoderma lucidum (W. Curt.: Fr.) Lloyd (Aphyllophoromycetideae) cooperatively induces tumor necrosis factor- $\alpha$ and interleukin- 6 with lipopolysaccharide by binding to dectin-1. Int. J. Med. Mush. 7, 193-200 (2005).

14. Choo, M.K., Park, E.K., Han, M.J. and Kim, D.H. : Antiallergic activity of ginseng and its ginsenoside. Planta Med. 69, 518-522 (2003).

15. Plaut, M., Pierce J.H., Whatson, C., Hanley-Hyde, J., Nordan, R.P. and Paul, W.E. : Mast cell lines produce lymphokines in response to cross-linkage of Fc epsilonRI or to calcium ionopore. Nature. 339, 64-67 (1989).

16. Simons, F.E.R.: The antiallergic effects of antihistamines (H1-receptor antagonists). J. Allergy Clin. Immunol. 90, 705715 (1992).

17. Stevens R.L. and Austen, K.F. : Recent advances in the cellular and molecular biology of mast cells. Immunol. Today. 10, 381-386 (1989).

18. Sakuma, S., Higashi, Y., Sato, N., Sasakawa, T., Sengoku, T., Ohkubo, Y., Amaya, T. and Goto, T. : Tacrolimus suppressed the production of cytokines involved in atopic dermatitis by direct stimulation of human PBMC system (Comparison 
with steroids). Int. Immunopharmacol. 1, 1219-1226 (2001).

19. Schafer-Korting, M., Schmid, M.H. and Korting, H.C. : Topical glucocorticoids with improved risk-benefit ratio. Drug Safety. 14, 375-385 (1996).

20. Kim, D.H. : Herbal medicines are activated by intestinal microflora. Nat. Prod. Sci. 8, 35-43 (2002).

21. Kobashi, K. and Akao, T. : Relation of intestinal bacteria to pharmacological effects of glycosides. Biosci. Microflora, 16, 1-7 (1997). 